\title{
Clinical pulmonary autograft valves: Pathologic evidence of adaptive remodeling in the aortic site
}

\author{
Elena Rabkin-Aikawa, MD, PhD \\ Masanori Aikawa, MD, PhD \\ Mark Farber, MS ${ }^{a}$ \\ Johannes R. Kratz, MS \\ Guillermo Garcia-Cardena, $\mathrm{PhD}^{\mathrm{a}}$ \\ Nicholas T. Kouchoukos, MD \\ Max B. Mitchell, MD \\ Richard A. Jonas, MD \\ Frederick J. Schoen, MD, $\mathrm{PhD}^{\mathrm{a}, \mathrm{f}}$
}

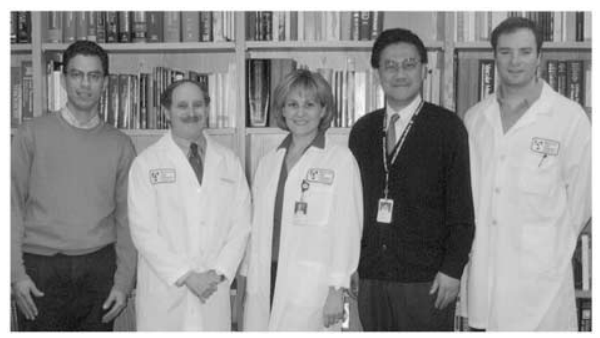

Objective: We studied the pathologic features, cellular phenotypes, and matrix remodeling of clinical pulmonary-to-aortic valve transplants functioning up to 6 years.

Methods: Nine autografts and associated vascular walls early (2-10 weeks) and late (3-6 years) postoperatively were examined by using routine morphologic methods and immunohistochemistry. In 4 cases autograft and homograft cusps were obtained from the same patients.

Left to right: Drs Garcia-Cardena, Schoen, Rabkin-Aikawa, Aikawa, and Farber

\begin{abstract}
From the Department of Pathology and the Cardiovascular Division, ${ }^{\mathrm{b}}$ Department of Medicine, Brigham and Women's Hospital, Harvard Medical School, Boston, Mass; Cardiac, Thoracic and Vascular Surgery, Inc, ${ }^{\text { }}$ St Louis, Mo; the Cardiac Surgery Department, ${ }^{\mathrm{d}}$ The Children's Hospital, University of Colorado Health Sciences Center, Denver, Colo; and the Department of Cardiovascular Surgery, ${ }^{e}$ Children's Hospital, and the Harvard-MIT Division of Health Sciences and Technology (HST), ${ }^{\mathrm{f}}$ Harvard Medical School, Boston, Mass.
\end{abstract}

Supported in part by National Heart, Lung, and Blood Institute grant PO1 HL-48743 (to Dr Peter Libby).

Received for publication Nov 20, 2003; revisions requested March 22, 2004; accepted for publication April 19, 2004.

Address for reprints: Frederick J. Schoen, $\mathrm{MD}$, PhD, Department of Pathology, Brigham and Women's Hospital, 75 Francis St, Boston, MA 02115 (E-mail: fschoen@partners.org).

J Thorac Cardiovasc Surg 2004;128:552-61 $0022-5223 / \$ 30.00$

Copyright (C) 2004 by The American Association for Thoracic Surgery

doi:10.1016/j.jtcvs.2004.04.016
Results: Autografts had near-normal trilaminar cuspal structure and collagen architecture and viable valvular interstitial and endothelial cells throughout the time course. In contrast, cusps of homografts used to replace the pulmonary valves in the same patients were devitalized. In early autograft explants, $19.3 \% \pm 2.4 \%$ of cuspal interstitial cells were myofibroblasts expressing $\alpha$-actin. In contrast, myofibroblasts comprised only $6.0 \% \pm 1.1 \%$ of cells in late explants and $2.5 \% \pm 0.4 \%$ and $4.6 \%$ $\pm 0.8 \%$ of cells in normal pulmonary and aortic valves, respectively $(P<.05)$. In early autografts only $12.0 \% \pm 4.6 \%$ of endothelial cells expressed the systemic arterial endothelial cell marker EphrinB2, whereas later explants had $85.6 \% \pm 5.4 \%$ of endothelial cells expressing EphrinB2 $(P<.05)$. In early autografts $43.8 \% \pm$ $8.8 \%$ of interstitial cells expressed metalloproteinase 13 , whereas late autografts had $11.4 \% \pm 2.7 \%$ of interstitial cells expressing matrix metalloproteinase $13(P<.05)$. Collagen content in autografts was comparable with that of normal valves and was higher than that seen in homograft valves $(P<.005)$. However, autograft walls were damaged, with granulation tissue (early) and scarring, with focal loss of normal smooth muscle cells, elastin, and collagen (late).

Conclusions: The structure of pulmonary valves transplanted to the systemic circulation evolved toward that of normal aortic valves. Key processes in this remodeling included onset of a systemic endothelial cell phenotype and reversible plasticity of fibroblast-like valvular interstitial cells to myofibroblasts.

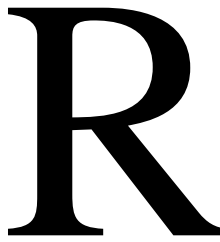

eplacement of a diseased aortic valve by means of transplantation of the patient's own pulmonary valve into the aortic position, first described by Donald N. Ross in 1967, ${ }^{1}$ has shown superior hemodynamic results in both pediatric and young adult patients. ${ }^{2-4}$ However, the pathologic features of pulmonary autograft valves (PAVs) have not been systematically described.

We documented the evolution of the morphologic features of clinical pulmonary autografts functioning up to 6 years, compared pulmonary autografts and cryopreserved homografts implanted in the same patients and removed simultaneously, and 
examined the changes in cellular phenotypes and extracellular matrix $(\mathrm{ECM})$ of PAV.

\section{Methods}

We studied 9 PAV cusps and 8 associated vascular walls collected from 4 centers after 2 to 10 weeks (early, $\mathrm{n}=3$ ) and 3 to 6 years (late, $n=6)$, at reoperation $(n=4)$, transplantation $(n=3)$ or autopsy $(n=2)$ from patients 3 to 49 years (mean, $25.9 \pm 18$ years) of age (Table 1). Cryopreserved homograft valves used for replacement of the pulmonary valves were obtained from 4 of the same patients (early, $\mathrm{n}=3$; late, $\mathrm{n}=1$ ). Nondiseased pulmonary valves $(n=5)$ and aortic valves $(n=5)$ obtained at autopsy served as control tissue. All valves were obtained according to a discarded tissue protocol approved by the Human Research Committee at Brigham and Women's Hospital.

\section{Histologic Characterization: General Morphology and ECM}

Specimens were fixed in $10 \%$ buffered formalin, and those not obtained at Brigham and Women's Hospital, Boston, Mass, were shipped as necessary. PAVs were dissected in the middle portion of the cusps through the adjacent wall, conventionally processed, and embedded in paraffin. Paraffin blocks were then stored until use. Sections were cut at $6 \mu \mathrm{m}$ and stained with hematoxylin and eosin for general morphology; Movat pentachrome stain for collagen, elastin, and proteoglycans; and picrosirius red viewed under polarized light for collagen architecture. ${ }^{5,6}$ Immunohistochemical and morphometric studies are described below.

\section{Characterization of Cell Phenotypes and Expression of Proteolytic Enzymes}

Markers of cell phenotypes and expression of proteolytic enzymes were identified by means of immunohistochemistry. Myofibroblasts were defined as cells showing antibody reaction to both $\alpha$-smooth muscle actin ( $\alpha$-SMA; microfilaments, Dako) and vimentin (intermediate filaments, Dako). ${ }^{7}$ Cells expressing vimentin only were classified as fibroblasts. Inflammatory cells were identified with antibodies to CD68 (macrophages, Dako) and CD45 (T cells, Dako). Mouse monoclonal antibody against the human matrix metalloproteinase 13 (MMP-13/collagenase 3, Calbiochem) was used to determine expression of proteolytic enzymes. MMP-13 staining was performed using antigen-unmasking pretreatment with commercially available proteinase K solution for 5 minutes at room temperature. Phenotypic changes of valvular endothelium were identified by antibodies to CD31 (Dako) and EphrinB2 (specific for arterial endothelial cells; preparation details below). ${ }^{8}$ Immunohistochemistry was done by using the avidinbiotin-peroxidase method. Macrophages $\left(\mathrm{CD}^{+} 8^{+}\right.$cells $)$in the valve cusps were used as an internal positive control for MMP-13 staining. ${ }^{9}$ Adjacent pulmonary artery and aortic wall served as internal control tissues for the EphrinB2 stain. Adjacent sections treated with nonimmune IgG served as negative controls.

\section{Development and Characterization of the Monoclonal Antibody for EphrinB2}

EphrinB2 is a marker of systemic arterial endothelium. ${ }^{8}$ Armenian hamsters were injected 3 times with $10 \mu \mathrm{g}$ of the extracellular domain of mEphrinB2 fused to Fc at weekly intervals. Serum was tested for EphrinB2 reactivity 2 weeks after the third injection. A booster injection $(10 \mu \mathrm{g})$ was given, and 3 days thereafter, hamsters were killed. Splenocytes were fused with SP2/0 murine myeloma cells. Two weeks after fusion, hybridoma supernatants were tested in ELISA assays. After limited dilution, one stable clone (5G9) was obtained. This clone was tested further by means of FACS analysis, immunoblotting, and immunohistochemistry.

\section{Cell and Collagen Quantitation and Statistical Analysis}

Valve thickness was measured with a linear eyepiece reticle (10 $\mathrm{mm}, 0.1 \mathrm{~mm}$ divisions; Fisher Scientific). Cell density was measured as the mean number of cells per 10 high-power fields $(400 \times)$ and expressed as cell numbers per square millimeter of the tissue section. The $\alpha$-SMA- and MMP-13-positive fraction was averaged over 5 representative high-power fields $(400 \times)$ ). The ratio of EphrinB2 ${ }^{+}$cells to total CD31-expressing cells was calculated for each cusp. Valvular collagen content was measured by means of a previously established technique. ${ }^{5}$ In brief, a color threshold was defined by using the negative background (black) for each sample. The collagen content was calculated by means of subtraction of the negative area from the total area of the valve. Statistical analysis used 1-way analysis of variance, followed by the Fisher test. Data were presented as means \pm SEM.

\section{Results}

Morphology of Pulmonary Autograft Valves

The morphologic features of early and late PAVs, normal pulmonary and aortic valves, and, where available, homograft valves are summarized in Figures 1 to 3 .

Valve cusps. Analogous to aortic (Figure 1, A, panels g and h), ${ }^{10}$ normal pulmonary valves had 3 well-defined tissue layers (Figure 1, A, panels a and b), each containing cells and characteristic ECM composition and configuration: (1) the fibrosa, rich in collagen; (2) the centrally located spongiosa, with loosely arranged collagen and proteoglycans; and (3) the ventricularis, enriched in elastic fibers. Both early and late PAV cusps (Figure 1, A, panels c-f) showed near-normal 3-layered structure and intact elastin; wellpreserved collagen microstructure detected with picrosirius red; usual outflow surface corrugations; minimal inflammatory cells, including macrophages (CD68) and T lymphocytes (CD45); and absence of calcification or thrombi.

Intimal thickening (pannus formation) was present on the ventricular aspect of some cusps, extending variably from the proximal to the distal portion of the valve. Because of pannus and increased underlying cuspal thickness, PAVs were approximately 3 times thicker than normal pulmonary valves and similar in thickness to aortic valves $(1.4 \pm 0.3$ $\mathrm{mm}$ for early, $0.9 \pm 0.2 \mathrm{~mm}$ for late, $0.3 \pm 0.1 \mathrm{~mm}$ for normal pulmonary, and $0.7 \pm 0.1 \mathrm{~mm}$ for normal aortic; Figure $1, B)$. Interstitial cell density was higher in both early and late PAVs than in normal valves (Figure 1, B). In particular, cell numbers were significantly increased in the fibrosa $\left(634 \pm 98\right.$ cells $/ \mathrm{mm}^{2}$ for early PAVs and $670 \pm 264$ 
TABLE 1. Clinical data

\begin{tabular}{|c|c|c|c|c|c|}
\hline Age/sex & Duration & Indication for PAV & Explantation circumstances & Source & $\begin{array}{c}\text { Tissue } \\
\text { examined }\end{array}$ \\
\hline \multicolumn{6}{|l|}{ Early } \\
\hline $38 / \mathrm{M}$ & $2 \mathrm{wk}$ & Calcific stenosis of CBAV & Myocardial infarction & Autopsy* & $A, H, W$ \\
\hline $7 / F$ & $8 w k$ & Tunnel-type subaortic stenosis, CBAV & Left ventricular failure & Transplant† & $A, H, W$ \\
\hline $13 / \mathrm{M}$ & $10 \mathrm{wk}$ & CBAV stenosis & Arrhythmia & Autopsyt & $A, H, W$ \\
\hline \multicolumn{6}{|l|}{ Late } \\
\hline $3 / \mathrm{M}$ & $2.5 \mathrm{y}$ & Calcific AV stenosis & $\begin{array}{l}\text { AVR, pulmonary hypertension, } \mathrm{PH} \\
\text { failure, mitral valve dysfunction }\end{array}$ & Transplant† & $A, W$ \\
\hline 38/M & $3.3 \mathrm{y}$ & Calcific stenosis of CBAV & $\begin{array}{l}\text { Biventricular hypertrophy, aortic } \\
\text { dilation }\end{array}$ & Transplant* & $A, H, W$ \\
\hline $48 / \mathrm{M}$ & 5 y & Calcification of CBAV & Aortic dilation with AVR & Reoperation $\ddagger$ & $A, W$ \\
\hline $13 / \mathrm{F}$ & 5.5 y & Complex congenital heart disease & Aortic dilation with AVR, calcified PH & Reoperation§ & $A$ \\
\hline 24/M & $6 y$ & Calcification of CBAV & Aortic dilation with AVR & Reoperation $\ddagger$ & $A, W$ \\
\hline $49 / \mathrm{M}$ & $6 y$ & CBAV & Aortic dilation with AVR & Reoperation $\ddagger$ & $A, W$ \\
\hline
\end{tabular}

$P A V$, Pulmonary autograft valve; $C B A V$, congenital bicuspid aortic valve; $A$, autograft cusp; $H$, homograft cusp; $W$, autograft wall; $A V$, aortic valve; $A V R$, aortic valve regurgitation; $P H$, pulmonary homograft.

*Brigham and Women's Hospital, Boston, Mass.

tUniversity of Colorado Health Sciences Center, Denver, Colo.

$\ddagger$ Cardiac, Thoracic and Vascular Surgery, Inc, St Louis, Mo.

§Children's Hospital, Boston, Mass.

cells $/ \mathrm{mm}^{2}$ for late PAVs) and ventricularis $(907 \pm 130$ cells $/ \mathrm{mm}^{2}$ for early PAVs and $732 \pm 243$ cells $/ \mathrm{mm}^{2}$ for late PAVs) but not spongiosa of PAVs relative to normal pulmonary valves had $378 \pm 147$ cells $/ \mathrm{mm}^{2}$ in the fibrosa and $381 \pm 182$ cells $/ \mathrm{mm}^{2}$ in the ventricularis $(P<.05)$.

Quantitative analysis of collagen demonstrated preserved collagen structure in PAV cusps $(62.7 \% \pm 5.7 \%$ for early PAVs and $62.8 \% \pm 6.7 \%$ for late PAVs) that was comparable with that of normal valves $(60.5 \% \pm 9.5 \%$ for pulmonary valves and $68.3 \% \pm 0.7 \%$ for aortic valves) and decreased collagen in homograft valve cusps $(33.3 \% \pm$ $7.7 \%, P<.005$ ) obtained from the same patients (Figure 1, C).

Aortic walls. PAV walls showed variable granulation tissue in early explants and loss of medial smooth muscle cells and elastin (Figure 2, A). They had lower collagen birefringence detected with picrosirius red under polarized light compared with that seen in normal valve walls (Figure $2, B)$. Late PAVs had variable disruption of structure, scarring, or both, without inflammation or calcification.

Comparison of pulmonary-to-aortic autografts and pulmonary homografts in the same patient. In contrast to the preserved architecture of PAVs, homograft valves from the pulmonary site implanted and removed simultaneously from 4 patients showed the following: (1) loss of interlayer demarcations; (2) flattening of outflow surface corrugations; (3) structural deterioration of ECM, with collagen hyalinization and loss of normal structural layers and cellularity; and (4) minimal tissue overgrowth (Figure 1, A, panels i-j). These findings on valve homografts confirm and the data below extend those previously reported by our laboratory. ${ }^{11}$
PAVs and homografts obtained from the same patients are compared in Figure 3. Cell density of early PAVs was greater than that of normal valves but decreased to nearnormal levels in late PAVs $\left(625 \pm 44\right.$ cells $/ \mathrm{mm}^{2}$ for early PAVs and $474 \pm 36$ cells $/ \mathrm{mm}^{2}$ for late PAVs vs $351 \pm 58$ cells $/ \mathrm{mm}^{2}$ for normal pulmonary valves and $310 \pm 59$ cells $/ \mathrm{mm}^{2}$ for normal aortic valves, $P<.05$ ). In contrast, homografts showed progressive loss of cells $(245,336,90$, and 29 cells $/ \mathrm{mm}^{2}$ at 2,8 , and 10 weeks and 3 years, respectively).

\section{Phenotypic Changes and Proteolytic Enzyme Expression in Interstitial Cells of Pulmonary Autograft Valves}

We compared the phenotype of interstitial cells in normal valves and PAV explants (Figure 4). In normal pulmonary and aortic valves only $2.5 \% \pm 0.4 \%$ and $4.6 \% \pm 0.8 \%$, respectively, of cells expressed $\alpha$-SMA; these cells were localized in the immediate subendothelium in the proximal (near the annulus) and middle portions (Figure 4, $A$, a and b, and Figure 4, B). In contrast, $19.3 \% \pm 2.4 \%$ of interstitial cells of early PAVs expressed $\alpha$-SMA, indicating modulation of the quiescent fibroblast-like interstitial cells of normal valves to myofibroblasts (Figure 4, A, d and e, and Figure $4, B$ ). Cells observed in overgrowing pannus expressed predominantly $\alpha$-SMA (Figure $4, A$, d). Late PAVs had limited $(6.0 \% \pm 1.1 \%)$ subendothelial distribution of $\alpha$-SMA ${ }^{+}$cells, which was similar to that seen in normal valves (Figure 4, $A, \mathrm{~g}$, h, and Figure 4, $B$ ).

Furthermore, $43.8 \% \pm 0.8 \%$ of interstitial cells in early PAVs expressed matrix remodeling enzymes (Figure 5). In 

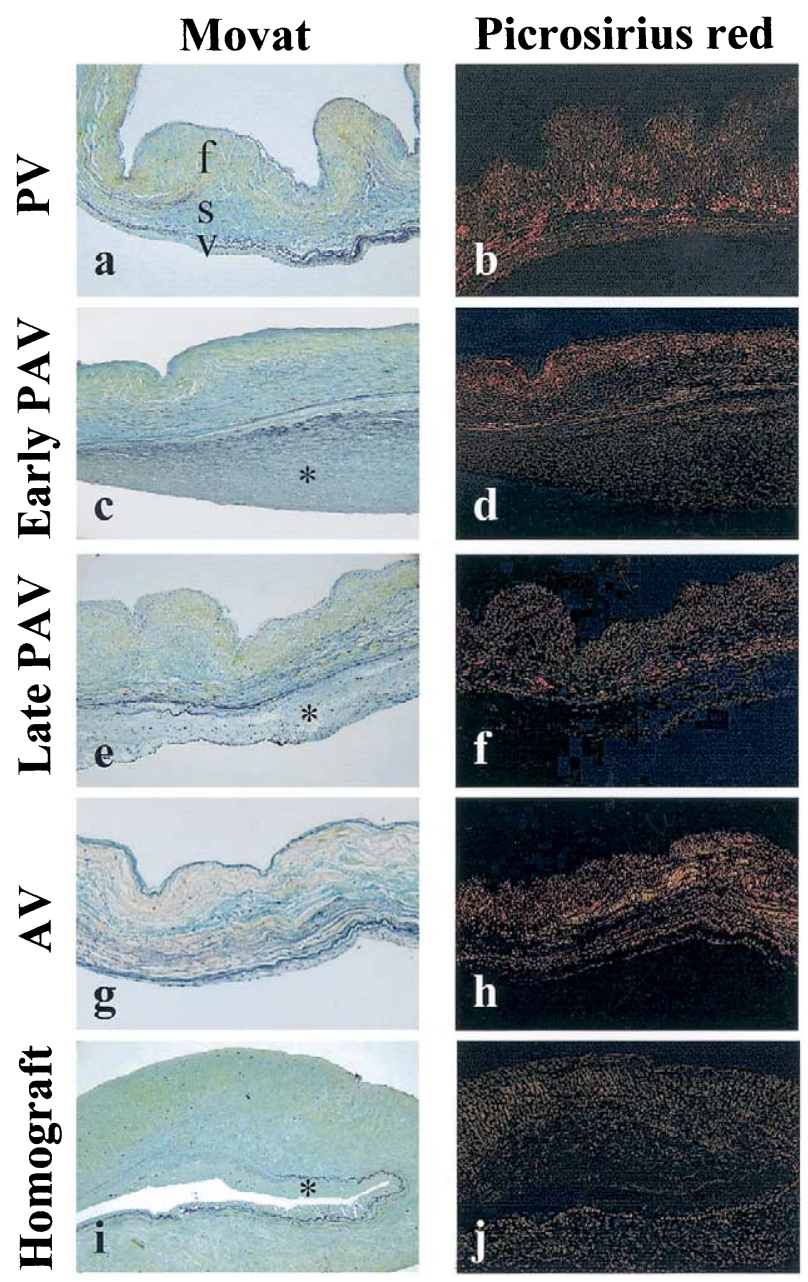

A
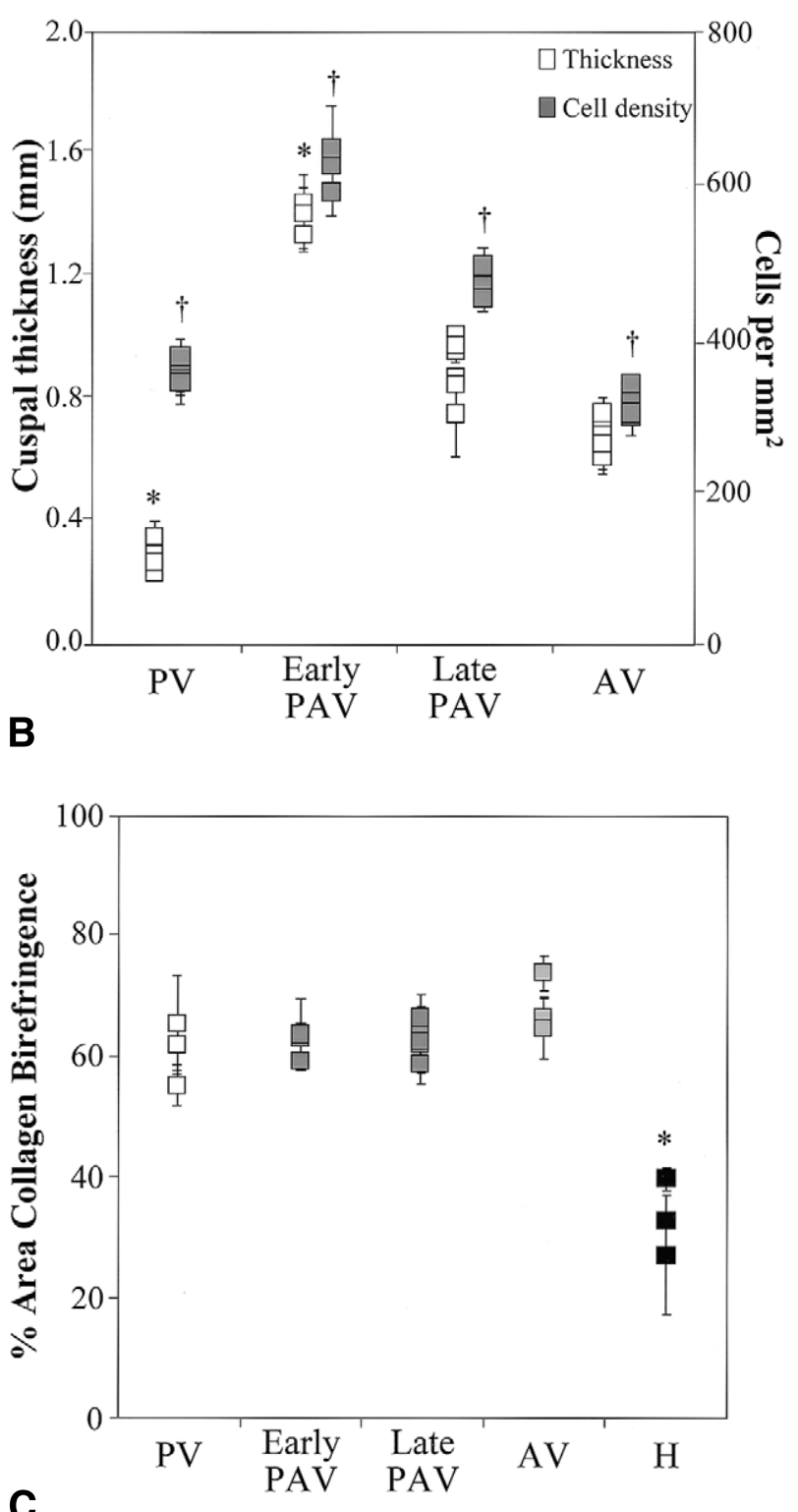

Figure 1. Morphologic features and collagenous architecture of PAVs. A, Three distinct layers are present in normal pulmonary valve (PV; $a-b)$ : the fibrosa (f), with an abundance of collagen (yellow); the spongiosa (s), with glycosaminoglycans (blue-green); and the ventricularis (v), with elastin (black). Both early and late pulmonary autografts (PAV; $c-f)$ showed near-normal 3-layered structure and intact elastin, usual outflow surface corrugations, and well-preserved collagen microstructure detected with picrosirius red. This was similar to that seen in normal aortic valves $(A V ; g$-h). Homograft valves $(i-j)$ showed loss of interlayer demarcations, flattening of the normal outflow surface corrugations, and structural deterioration of the ECM revealed with picrosirius red staining under polarized light, which demonstrated that collagen fibers were almost undetectable and had lower birefringence than those in normal valves. (Original magnification of all panels $100 \times$.) *Pannus formation. B, Valve thickness and interstitial cell density in PAVs compared with those in normal aortic valves (AV) and pulmonary valves (PV). *Significant differences between all combinations of pulmonary valves and early PAVs versus late PAVs and aortic valves $(P<.05)$; tsignificant differences in cell density between all sets of valves $(P<.05)$; no difference was found between pulmonary valves and aortic valves. C, Collagen accumulation in PAVs compared with that in normal aortic valves (AV), pulmonary valves (PV), and homograft valves (H). *Statistically significant decrease in collagen content in homograft valves compared with that in PAVs and normal valves. 

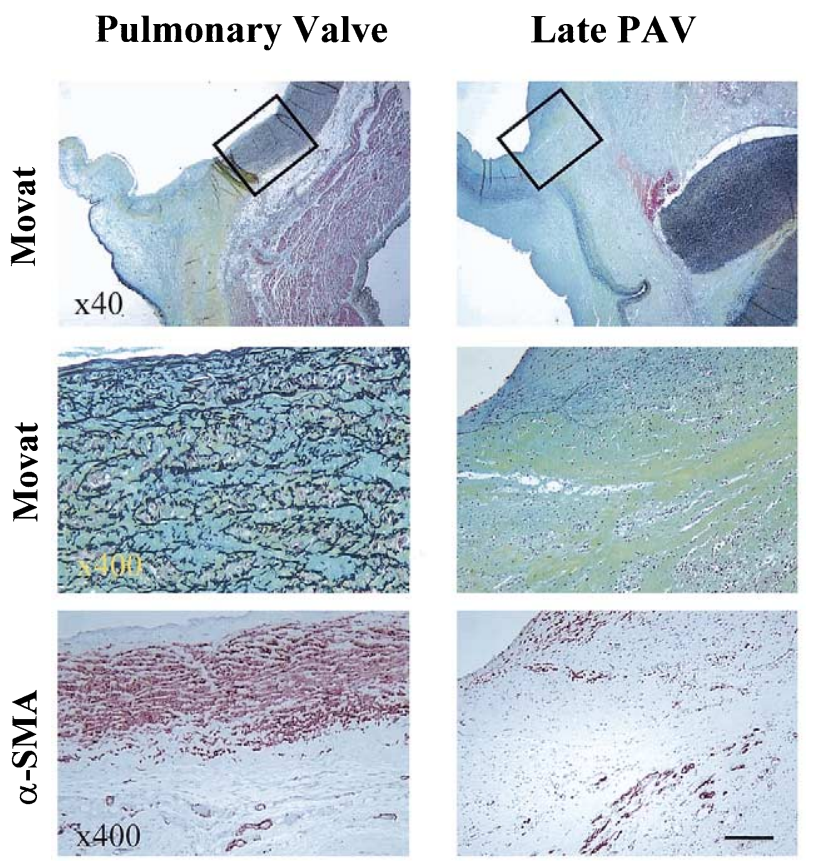

A
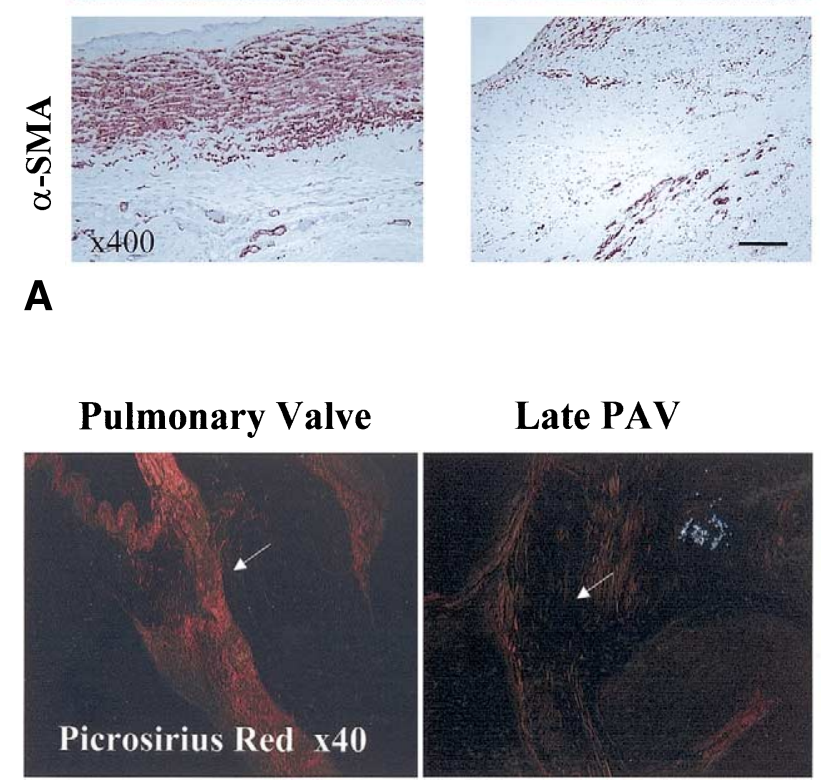

\section{B}

Figure 2. Arterial wall of pulmonary autografts. A, Movat pentachrome stain shows overall morphologic features of a normal pulmonary valve compared with that of a PAV and associated arterial wall (top). (Original magnification $40 \times$.) The middle panel demonstrates loss of elastin (black) and accumulation of collagen (yellow), suggesting scarring formation in late PAVs. (Original magnification $400 \times$.) Immunohistochemistry for $\alpha$-SMA shows loss of medial smooth muscle cells (bottom) in late PAVs. (Original magnification $400 \times$; bar $=50 \mu \mathrm{m}$.) B, Late PAV walls showed lower collagen birefringence compared with that seen in normal valve wall (arrows). (Original magnification $40 \times$.)

contrast, only $11.4 \% \pm 2.7 \%$ of interstitial cells of late explants expressed MMP-13 $(P<.005)$. Normal aortic and pulmonary valves expressed miniscule amounts of MMP-13 ( $0.7 \%$ and $0.3 \%$, respectively).

Homografts had no detectable immunoreaction to vimentin, $\alpha$-SMA, or MMP-13.
Autograft valves
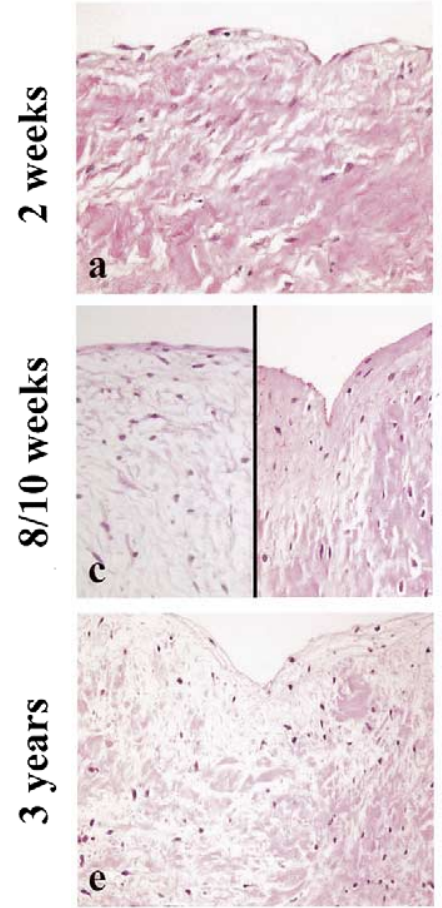

\section{Homograft valves}
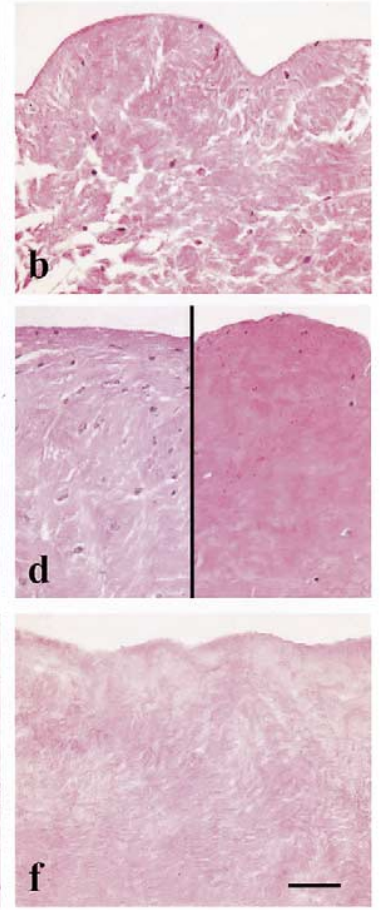

Figure 3. Comparative morphologic features of autografts and homografts obtained from the same patients. Autograft valves had near-normal structure and cellular population $(a, c$, and $e)$. In contrast, homografts from the same patients $(b, d$, and $f)$ had progressive collagen hyalinization and loss of cellularity. (Original magnification 400 ; bar $=50 \mu \mathrm{m}$.)

\section{Phenotypic Changes of Endothelial Cells of Pulmonary Autograft Valves}

As seen in Figure 6, and similar to results seen in normal valves, early and late PAVs were covered by a layer of $\mathrm{CD} 1^{+}$endothelial cells. To elucidate the phenotypic differences between aortic and pulmonary valve endothelium, we stained aortic and pulmonary valves with an antibody for EphrinB2 (a marker of arterial endothelium ${ }^{8}$ ). EphrinB2 was detected nearly uniformly $(98.8 \% \pm 3.2 \%)$ in endothelial cells of normal aortic but not pulmonary valves (Figure 6). PAVs were stained with EphrinB2 antibody to determine whether transplantation of pulmonary valves to the aortic position (with higher transvalvular pressure gradient, flow, and oxygen tension) could modulate the phenotype of endothelial cells. Valvular endothelial cells of early PAV explants had only patchy expression of EphrinB2 on both inflow and outflow surfaces $(12.0 \% \pm 4.6 \%)$. However, an increased population of endothelial cells expressed the $\mathrm{CD} 1^{+} /$EphrinB2 $^{+}$phenotype $(85.6 \% \pm 5.4 \%)$ in late PAVs (Figure 6). In contrast, homografts from the same patients had neither $\mathrm{CD}_{3} 1^{+}$nor EphrinB2 ${ }^{+}$cells. 


\section{Discussion}

A fundamental problem inherent in the use of other existing biologic valve substitutes is their lack of viability and consequent failure to remodel ECM, repair structural injury, and potentially adapt to the somatic growth of pediatric recipients. ${ }^{12}$ This study shows that in contrast to other contemporary biologic valve substitutes and similar to natural valves, PAV transplants uniquely preserve interstitial and endothelial cell viability, remodel ECM, adapt to new environmental demands, and potentially grow. PAVs maintained functional collagen architecture and cell viability after 3 to 6 years. There was minimal inflammation and no calcific deposits or thrombi. Interstitial cells in these PAVs were initially activated and later normalized both interstitial and endothelial cell phenotypes toward those of normal aortic valves. PAV cusps were as thick as aortic cusps, in part because of increased intimal thickening and deep cellularity, possibly as a result of cell proliferation or progenitor cell recruitment.

\section{Comparison of Autograft and Homograft Valves}

In contrast to the preserved cells and ECM of PAVs, homografts had progressive loss of cells and structural deterioration. As we previously described, ${ }^{11}$ progressive loss of interstitial cells associated with a lack of active metabolic functions and ECM production in homografts suggests that their durability depends critically on the quality of their original collagen. Moreover, the largely normal structure and cellular population of PAVs were similar to those of aortic valves from orthotopic heart transplants. ${ }^{11}$ In contrast to isolated homograft valve replacements, valves from transplanted hearts suffer less ischemic time and no cryopreservation.

\section{Adaptive Remodeling of Clinical Pulmonary Autograft Valves}

Heart valves have a layered architecture and highly specialized, functionally adapted ECM, ${ }^{10,13}$ which collectively accommodate repetitive changes in shape and dimension throughout the cardiac cycle. In normal valves interstitial valvular cells synthesize ECM and mediate its ongoing repair and remodeling. In existing biologic valve substitutes, cells are nonviable, adaptive remodeling of ECM cannot occur, and repair of structural injury is impossible. This often results in impaired durability caused by calcification and collagen deterioration. ${ }^{12,13}$

The major cell population of normal cardiac valves is comprised of fibroblast-like interstitial cells. Recently, it has been demonstrated that mechanical forces ${ }^{14}$ or injury ${ }^{15}$ can induce phenotypic changes in valvular cells. The present study demonstrates transient activation of valvular interstitial cells to myofibroblasts in vivo in response to environmental change. Nevertheless, the mechanisms inducing and regulating the interstitial cell response to physical signals

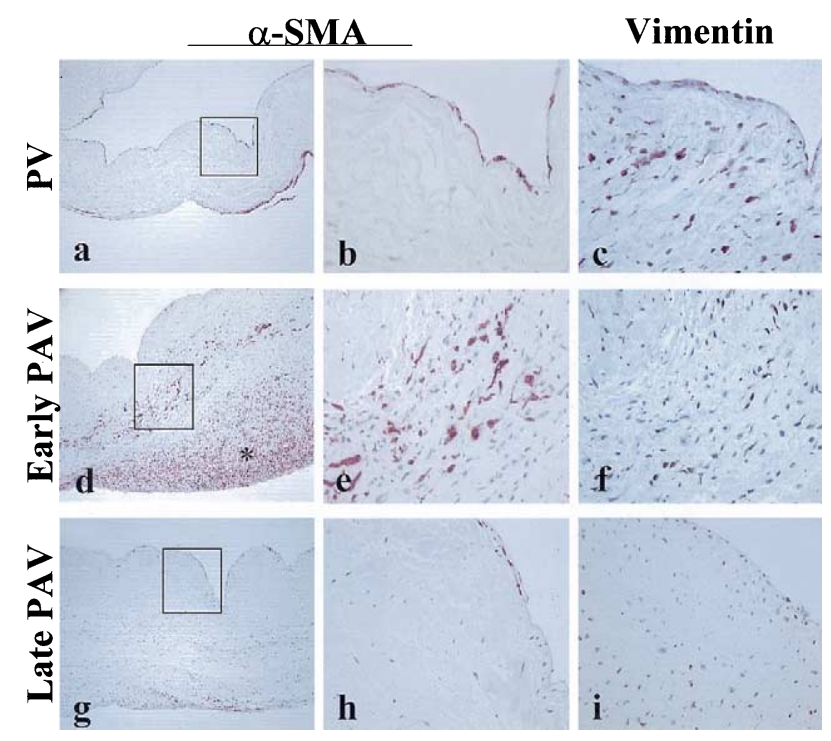

A

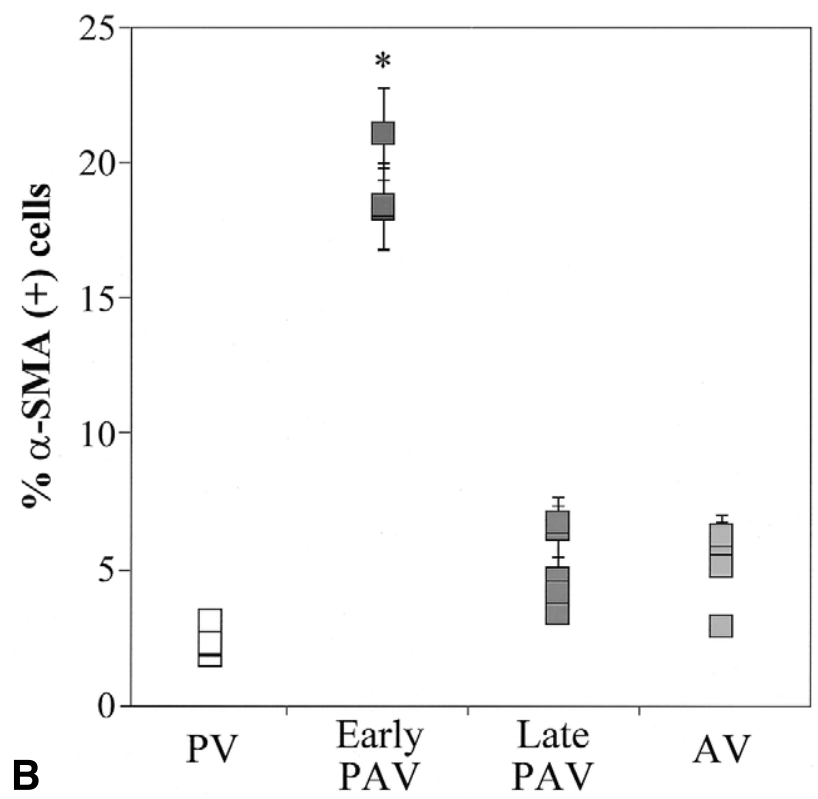

Figure 4. Immunophenotypes of interstitial cells of normal pulmonary valves and autograft explants. A, In normal pulmonary valves (PV) fibroblast-like interstitial cells expressed predominantly vimentin but not $\alpha$-SMA (a-c). Cells that stained positive for $\alpha$-SMA were localized immediately below the endothelium. *Pannus formation in early PAVs (d). In early PAVs a large population of cells in the spongiosa and the ventricularis expressed both vimentin and $\alpha$-SMA, suggesting modulation to myofibroblasts in early PAVs (d-f). In late PAVs the subendothelial distribution of $\alpha$-SMA ${ }^{+} /$vimentinpositive myofibroblasts among the interstitial cells resembled the quiescent fibroblast-like cell population of the normal valves $(g-i)$. (original magnification: $a, d$, and $g, 100 \times ; b, c, e, f, h$, and $i, 400 \times$. ) $\mathrm{B}$, An initial increase in the number of $\alpha$-SMA ${ }^{+}$cells in early PAVs eventually normalized to aortic valve (AV) levels in late PAVs. *Difference between early PAVs and all other valve combinations ( $P$ $<$.01). PV, Pulmonary valve. 


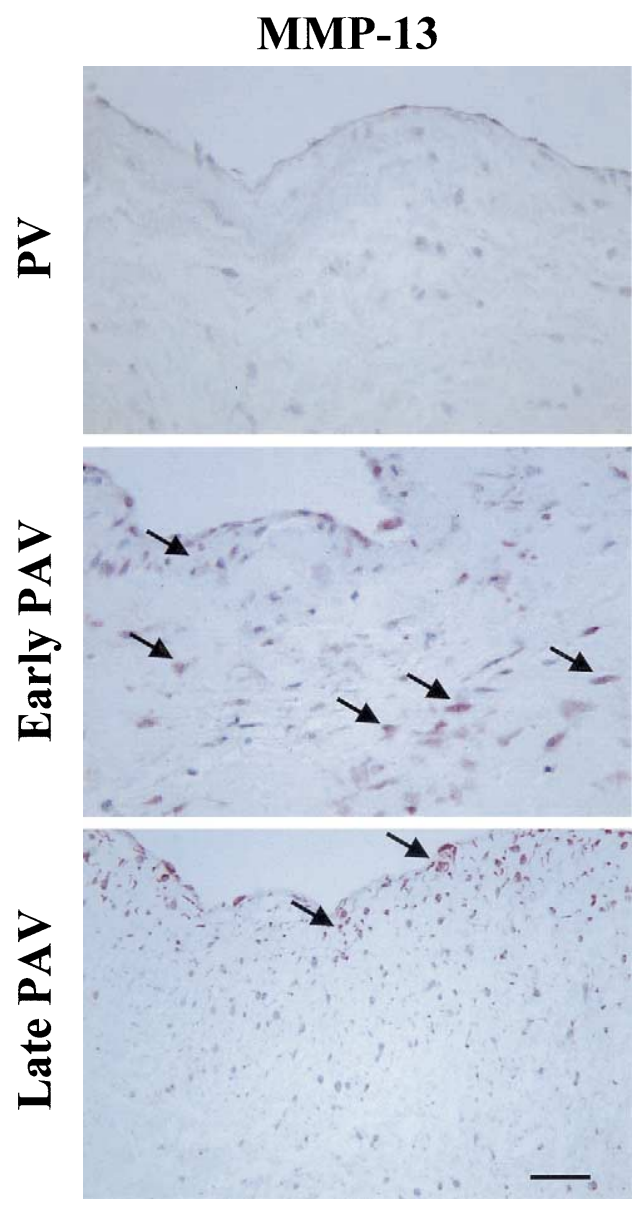

A

B

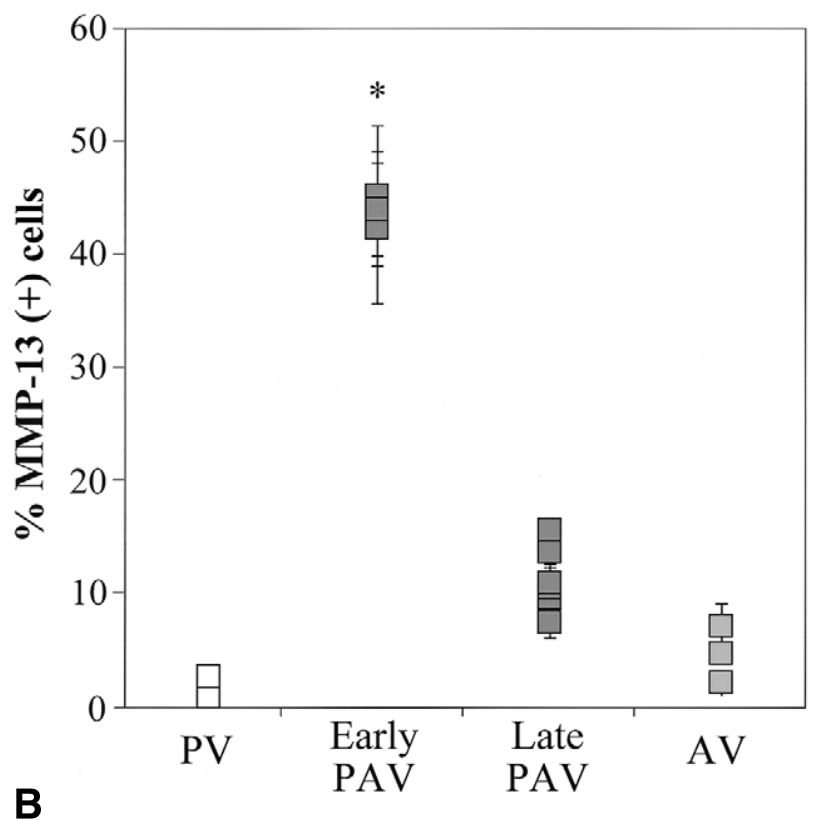

Figure 5. Proteolytic enzyme expression in pulmonary autografts compared with that seen in normal valves. A, Interstitial cells in the early PAVs expressed higher levels of MMP-13 than normal valves. In late PAVs only a few superficial cells showed weak expression of MMP-13, suggesting cuspal intimal proliferative lesion formation. (Original magnification 400x; bar $=50 \mu \mathrm{m}$.) PV, Pulmonary valve. B, An initial increase in the number of interstitial cells expressing MMP-13 in early PAVs decreases to aortic valve (AV) and pulmonary valve (PV) levels in late PAVs. *Significant difference in MMP-13 expression in early PAVs compared with that seen in late PAVs and normal valves.

are largely unknown. Our previous studies also suggest phenotypic modulation of interstitial cells as a response to injury in clinical mitral valves with myxomatous degeneration $^{6}$ and experimental tissue-engineered heart valves. ${ }^{16}$ Interestingly, the persistence of the myofibroblast phenotype in myxomatous valves removed at surgical intervention suggests that, in contrast to PAVs, mechanical equilibrium is not ultimately achieved. ${ }^{6}$ The signaling pathways and gene expression patterns characteristic of responses to vascular endothelial and vascular smooth muscle cells to mechanical stress might be operative in both valvular endothelial and interstitial cells. ${ }^{17}$

Interstitial collagenases mediate the initial step of collagen degradation through breakdown of the native helix of the fibrillar collagen network (type I is most abundant, comprising approximately $70 \%$ of the total collagen in valves). ${ }^{10,18}$ MMPs, particularly MMP-13, are also involved in ECM breakdown in normal tissues and in pathologic cardiovascular conditions, such as atherosclerosis, ${ }^{9}$ aortic aneurysms, ${ }^{19}$ and myxomatous valve degeneration. ${ }^{6}$ Early PAVs had increased expression of MMP-13 by interstitial cells, probably as an early cell activation response to surgical trauma and subsequent collagen remodeling. However, late PAVs had lesser expression of MMP-13 comparable with that seen in normal valves. Collagen birefringence detected with picrosirius red under polarized light was stronger in both groups of PAVs compared with that seen in homograft valve cusps. 

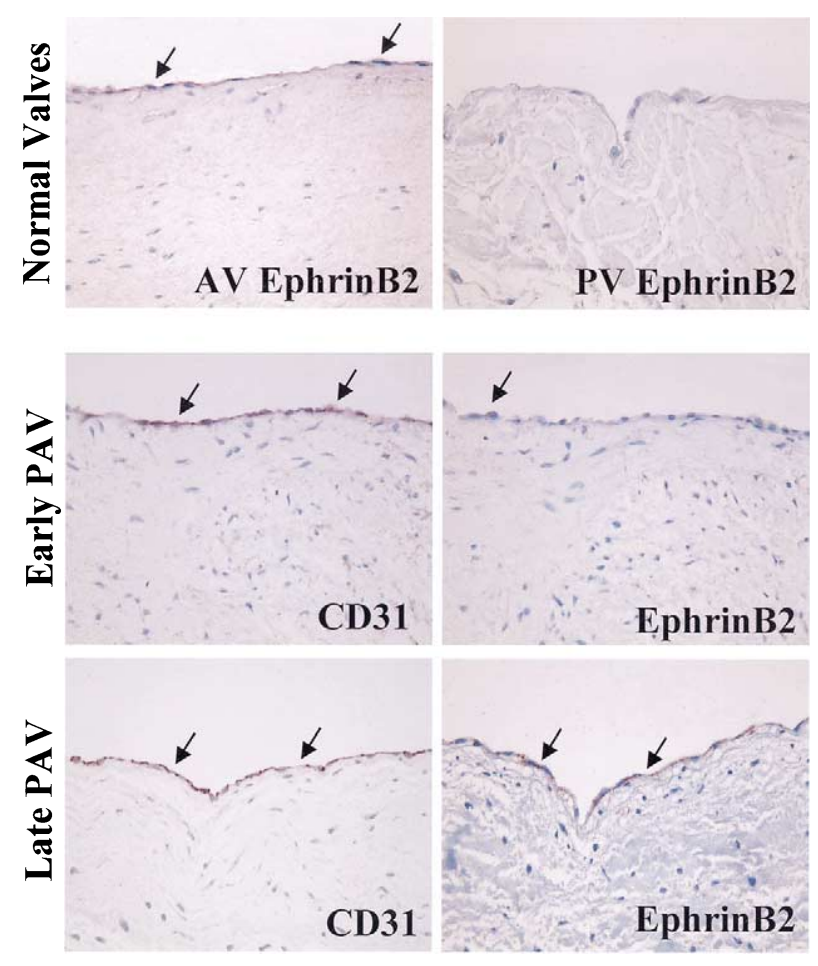

A

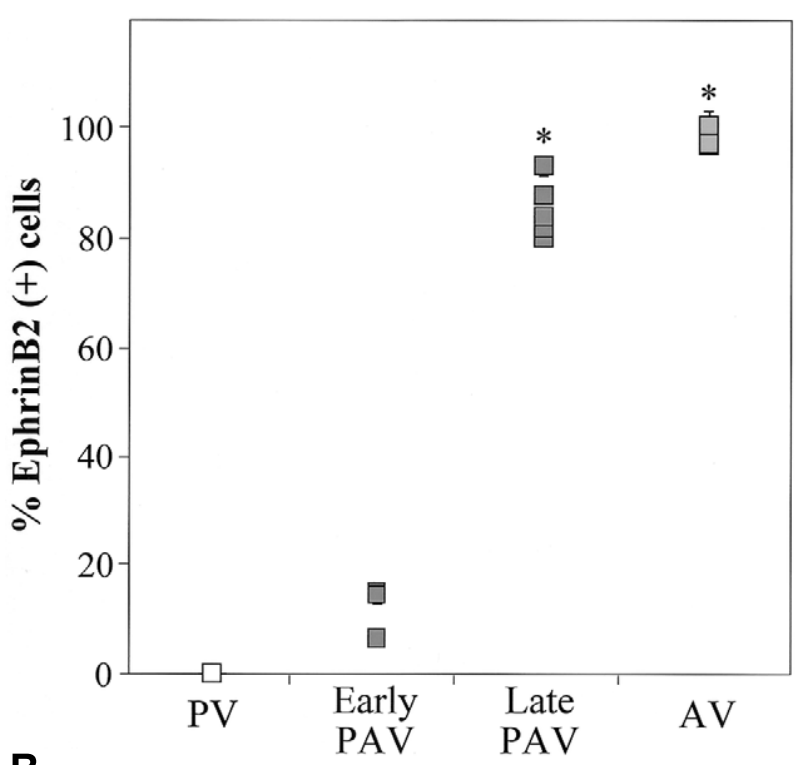

Figure 6. Immunophenotype of endothelial cells of normal valves and autograft explants. A, EphrinB2 was detected in normal aortic valve (AV) but not pulmonary valve (PV) endothelium (top panels). Endothelial cells of early PAVs had patchy expression of EphrinB2 (arrow, middle panels), whereas an increased population of endothelial cells expressed the $\mathrm{CD}^{+}{ }^{+} /$EphrinB2 $^{+}$phenotype in late PAVs (bottom). (Original magnification $400 \times$.) B, Progressive increase of EphrinB2 expression in PAVs toward levels of a normal aortic valve (AV). *Significant differences between late PAVs and aortic valves versus pulmonary valves $(P V s)$ and early $\operatorname{PAVs}(P<.01)$.

\section{Valvular Endothelial Cell Adaptation}

EphrinB2 identifies a stable genetic difference between arterial and venous endothelial cells. ${ }^{8}$ We demonstrated that endothelial cells from normal human aortic but not pulmonary valves express EphrinB2. Moreover, early PAV cusps showed only sporadic expression of EphrinB2, although late PAV explants had strong EphrinB2 expression.

Our data provide the first demonstration in vivo in human subjects that endothelial cells covering valves of leftsided but not right-sided heart valves express EphrinB2 and suggest that this expression can be induced by alterations in the local valvular environment. It is probable that this change in valvular endothelial cell phenotype in the PAV was due to altered mechanical stress, oxygen tension, or both, which is different in the systemic compared with the pulmonary circulation. However, it is uncertain that the endothelial cells present on the cusps of the explant were derived from those present initially because repopulation of transplanted valve tissue by circulating endothelial progenitor cells ${ }^{20}$ or cell migration across the anastomosis from the adjacent preexisting aortic wall cannot be excluded.

\section{Clinical Implications}

This work describes changes in cells and ECM that accompany the evolution of the PAV from a structure characteristic of the pulmonary valve to one resembling the aortic valve. These changes are likely driven by the combined effects of biomechanical forces, oxygen tension, and perioperative trauma. However, irrespective of the mechanisms involved, the presence of functionally intact interstitial cells in PAV cusps suggests that these valve substitutes are capable of ongoing repair of the valvular collagen and other ECMs, adaptation, and potentially growth by means of cell proliferation and matrix synthesis. These features are not exhibited by glutaraldehyde-pretreated bioprostheses, cryopreserved homograft valves, or other contemporary tissue valve substitutes.

In contrast to the high quality of the PAV cuspal tissue, the pulmonary autograft walls examined in the present study were not well preserved and showed extensive structural disruption. One potential cause of these changes is the disruption of the vasa vasorum by surgical dissection. Moreover, most of the patients in our study had congenitally 
bicuspid aortic valves; such individuals have a relatively high frequency of histologic abnormalities of the aorta and pulmonary arterial walls and a susceptibility to dilation of the aortic root and ascending aorta, ${ }^{21}$ probably caused by smooth muscle cell apoptosis, ${ }^{22}$ and deficient ECM and matrix remodeling. ${ }^{23}$ This suggests that an intrinsic structural abnormality might have contributed to the observed dilation in the majority of late clinical specimens examined in this study. We are unaware of associated pulmonary valvular cuspal histologic abnormalities in patients with congenitally bicuspid aortic valve. The histologic results in the 7 patients with and the 2 patients without bicuspid valves were consistent, and we believe that it was reasonable to combine the data from cusps obtained from those patients. Although aneurysmal expansion of the aortic root of clinical significance occurs only in a minority of PAV recipients, ${ }^{2,24}$ experimental and clinical studies suggest that the aortic roots of PAVs increase in diameter to a greater extent than would be expected through normal growth ${ }^{25-29}$ and that passive dilation might play a role. However, the present study does not permit a distinction between passive dilation and active growth.

\section{Limitations of This Study}

The retrospective analysis of these unusual surgical specimens pooled from several institutions in this study enabled us to answer important questions regarding the fate of PAVs. Nevertheless, this study has several limitations. Treatment of the study specimens was nominally the same, but we cannot absolutely exclude heterogeneity in specimen procurement procedures and tissue handling that could be important. Because of a limited number of specimens and the lack of truly sequential information on a specific specimen, our findings are only suggestive of mechanisms. The cause of aortic wall dilation in these patients and the role in aortic dilation of preexisting abnormalities of the vasculature in the patients with bicuspid valves could not be determined.

\section{Conclusions}

This study shows that PAVs respond to mechanical and other characteristics of the systemic circulation. Our study suggests new insight into the mechanisms of ECM remodeling in heart valves in general and the adaptation of PAVs to their new environment. These data show that the interstitial cells of clinical pulmonary autografts are viable and exhibit considerable plasticity; they respond to altered conditions by means of reversible phenotypic changes and increased expression of proteolytic enzymes associated with ECM remodeling. Collectively, this and previous studies are consistent with a hypothetic general paradigm by which valves adapt to environmental changes: under mechanical stresses and other stimuli, the interstitial cells become acti- vated and mediate connective tissue remodeling until mechanical equilibrium is restored and the cells return to the quiescent state. Moreover, endothelial cells can also appropriately adjust their phenotype to accommodate an altered environment.

\section{References}

1. Ross DN. Replacement of aortic and mitral valves with a pulmonary autograft. Lancet. 1967;2:956-8.

2. Elkins RC, Knott-Graig CJ, Kent EW, et al. Pulmonary autograft in children: realized growth potential. Ann Thorac Surg. 1994;57:138794.

3. Kouchoukos NT, Davila-Roman VG, Spray TL, et al. Replacement of the aortic root with a pulmonary autograft in children and young adults with aortic-valve disease. $N$ Engl J Med. 1994;330:1-6.

4. Chambers J, Somerville J, Stone S, et al. Pulmonary autograft procedure for aortic valve disease. Circulation. 1997;96:2206-14.

5. Aikawa M, Rabkin E, Okada Y, et al. Lipid lowering by diet reduces matrix metalloproteinase activity and increases collagen content of rabbit atheroma: a potential mechanism of lesion stabilization. Circulation. 1998;97:2433-44.

6. Rabkin E, Aikawa M, Stone JR, et al. Activated interstitial myofibroblasts express catabolic enzymes and mediate matrix remodeling in myxomatous heart valves. Circulation. 2001;104:2525-32.

7. Schurch W, Seemayer TA, Gabbiani G. The myofibroblast: a quarter century after its discovery. Am J Surg Pathol. 1998;22:141-7.

8. Shin D, Garcia-Cardena G, Shin-Ichiro H, et al. Expression of EphrinB2 identifies a stable genetic difference between arterial and venous vascular smooth muscle as well as endothelial cells, and marks subsets of microvessels at sites of adult neovascularization. Dev Biol. 2001; 230:139-50.

9. Sukhova GK, Schoenbeck U, Rabkin E, et al. Evidence for increased collagenolysis by interstitial collagenases-1 and -3 in vulnerable human atheromatous plaques. Circulation. 1999;99:2503-9.

10. Schoen FJ. Aortic valve structure-function correlations: role of elastic fibers no longer a stretch of the imagination. J Heart Valve Dis. 1997;6:1-6.

11. Mitchell RN, Jonas RA, Schoen FJ. Pathology of explanted cryopreserved allograft heart valves: comparison with aortic valves from ortotopic heart transplants. J Thorac Cardiovasc Surg. 1998;115:11827.

12. Schoen FJ. Future directions in tissue heart valves: impact of recent insights from biology and pathology. J Heart Valve Dis. 1999;8:350-8.

13. Schoen FJ, Levy RJ. Tissue heart valves: current challenges and future research perspectives. J Biomed Mater Res. 1999;47:439-65.

14. Weston MW, Yoganathan AP. Biosynthetic activity in heart valve leaflets in response to in vitro flow environments. Ann Biomed Eng. 2001;29:752-63.

15. Tamura K, Jones M, Yamada I, et al. Wound healing in the mitral valve. J Heart Valve Dis. 2000;9:53-63.

16. Rabkin E, Hoerstrup SP, Aikawa M, et al. Evolution of cell phenotype and extracellular matrix in tissue-engineered heart valves during in vitro culture and in vivo remodeling. J Heart Valve Dis. 2002;11:30814.

17. Ingber DE. Mechanical signaling and the cellular response to extracellular matrix in angiogenesis and cardiovascular physiology. Circ Res. 2002;91:877-87.

18. Visse R, Nagase H. Matrix metalloproteinases and tissue inhibitors of metalloproteinases: structure, function and biochemistry. Circ Res. 2003;92:827-39.

19. Mao D, Lee JK, VanVickle SJ, Thompson RW. Expression of collagenase-3 (MMP-13) in human abdominal aortic aneurisms and vascular smooth muscle cells in culture. Biochem Biophys Res Commun. 1999;261:904-10.

20. Rafii S, Lyden D. Therapeutic stem and progenitor cell transplantation for organ vascularization and regeneration. Nat Med. 2003; 9:702-12. 
21. de Sa M, Moshkovitz Y, Butany J, et al. Histologic abnormalities of the ascending aorta and pulmonary trunk in patients with bicuspid aortic valve disease: clinical relevance to the Ross procedure. $J$ Thorac Cardiovasc Surg. 1999;118:588-94.

22. Bonderman D, Gharehbaghi-Schnell E, Wollenek G, Maurer G, Baumgartner H, Lang IM. Mechanisms underlying aortic dilatation in congenital aortic valve malformation. Circulation. 1999;99:2138-43.

23. Fedak PWM, de Sa MPL, Verma S, et al. Vascular matrix remodeling in patients with bicuspid aortic valve malformations: implications for aortic dilatation. J Thorac Cardiovasc Surg. 2003;126:797-806.

24. Schmidt FK, Hilker M, Kampman C, et al. Clinical performance of native pulmonary valve in the systemic circulation. $J$ Heart Valve Dis. 1988;7:620-5.

25. Solymar L, Sudow G, Holmgren D. Increase in size of the pulmonary autograft after the Ross operation in children: growth or dilation? J Thorac Cardiovasc Surg. 2000;119:4-9.

26. Sievers HH, Leyh R, Loose R, et al. Time course dimension and function of the autograft pulmonary root in the aortic position. $J$ Thorac Cardiovasc Surg. 1993;105:775-80.

27. Hokken RB, Bogers AJJC, Taams MA, et al. Does the pulmonary autograft in the aortic position in adults increase in diameter? An echocardiographic study. J Thorac Cardiovasc Surg. 1997;113:66774.

28. David TE, Omran A, Ivanov J, et al. Dilation of the pulmonary autograft after the Ross procedure. J Thorac Cardiovasc Surg. 2000; 119:210-20.

29. Luciani GB, Casali G, Favaro A, et al. Fate of the aortic root late after Ross operation. Circulation. 2003;108(suppl II):II61-7. 